Citation: P. Tsopelas, N. Soulioti, M.J. Wingfield, I. Barnes, S. Marincowitz, E.C. Tjamos, E.J. Paplomatas (2021) Ceratocystis ficicola causing a serious disease of Ficus carica in Greece. Phytopathologia Mediterranea 60(2): 337-349. doi: 10.36253/phyto-12794

Accepted: June 22, 2021

Published: September 13, 2021

Copyright:@2021 P. Tsopelas, N. Soulioti, M.J. Wingfield, I. Barnes, S. Marincowitz, E.C. Tjamos, E.J. Paplomatas. This is an open access, peer-reviewed article published by Firenze University Press (http://www.fupress.com/pm) and distributed under the terms of the Creative Commons Attribution License, which permits unrestricted use, distribution, and reproduction in any medium, provided the original author and source are credited.

Data Availability Statement: All relevant data are within the paper and its Supporting Information files.

Competing Interests: The Author(s) declare(s) no conflict of interest.

Editor: Jean-Michel Savoie, INRA Villenave d'Ornon, France.

\section{Research Papers \\ Ceratocystis ficicola causing a serious disease of Ficus carica in Greece}

\author{
Panaghiotis TSOPElaS ${ }^{1, *}$, Nikoleta SOUlioti ${ }^{1}$, Michael J. \\ WINGFIELD ${ }^{2}$, IRENE BARNES ${ }^{2}$, SEONJU MARINCOWITZ ${ }^{2}$, ELEFTHerios C. \\ TJAMOS ${ }^{3}$, EPAMINONDAS J. PAPLOMATAS 3 \\ ${ }^{1}$ Institute of Mediterranean Forest Ecosystems, Terma Alkmanos, 11528 Athens, Greece \\ ${ }^{2}$ University of Pretoria, Department of Biochemistry, Genetics and Microbiology, Forestry \\ and Agricultural Biotechnology Institute (FABI), Pretoria, South Africa \\ ${ }^{3}$ Laboratory of Plant Pathology, Agricultural University of Athens, Athens, Greece \\ ${ }^{*}$ Corresponding author. E-mail: tsop@fria.gr
}

\begin{abstract}
Summary. Ceratocystis ficicola causes vascular wilt of fig trees in Japan, invading root systems and the main stems eventually leading to tree death. In surveys from 2018 to 2020 in fig orchards in Greece, this fungus was detected in two separated regions. The fungus was consistently isolated from infected wood and from rhizosphere soil. The isolates were identified based on multi-locus phylogenetic analyses of $r p b 2, b t 1$ and tef1 gene regions and detailed morphological characteristics, including comparisons with an ex-type isolate of C. ficicola from Japan. The pathogenicity of Greek isolates was proven on Ficus carica and F. benjamina plants. Ceratocystis ficicola is a soilborne pathogen, and the occurrence of vascular wilt outbreaks suggest that the pathogen spreads within and between orchards with infested soil and wood debris during ploughing. The pathogen is also spreading in Greece with infected propagation material. This is the first detailed report of C. ficicola outside Japan, and there is concern over potential spread of the pathogen to other Mediterranean countries, where approx. $70 \%$ of the world fig production occurs.
\end{abstract}

Keywords. Ceratocystis ficicola, Ficus carica, soil-borne pathogen, vascular wilt, Greece.

\section{INTRODUCTION}

Fig (Ficus carica L.) is one of the oldest domesticated tree crops globally. According to Kislev et al. (2006) this tree was cultivated for its fruit during the Early Neolithic period (11,400 to 11,200 years ago), preceding cereal domestication. Ficus (Moraceae) includes more than 700 species, native to the tropics or sub-tropics. Ficus carica is indigenous to the Middle East and Asia Minor, and is mostly cultivated in warm and dry areas of the Mediterranean region (Condit, 1955; Flaishman et al., 2008). Ficus carica has been cultivated in Greece since ancient times, as mentioned by Homer (8th century BC) The Odyssey, and Theophrastus (4-3rd century BC) described cross- 
fertilization of wild and domesticated figs (Condit, 1955). Fig continues to be an important crop, in Greece, where production in 2019 was 19,730 t (FAO, 2019). Thus, any negative impact on these trees due to serious disease is considered important from both a cultural and an economic standpoint.

Since the 1970s, a serious disease caused by a Ceratocystis species has been reported in Japanese fig orchards. The causal agent of this disease was initially attributed to Ceratocystis fimbriata sensu lato (Kato et al., 1982). Kajitani and Masuya (2011) described the pathogen as a new species, Ceratocystis ficicola Kajitani and Masuya, based on discernable morphological characteristics and DNA sequence data. Like many other Ceratocystis species, C. ficicola is a soil-borne pathogen that infects roots and main stems of susceptible hosts, causing vascular wilt and eventually tree death. The pathogen is dispersed by human activities, mainly with contaminated plant material, and has spread to many fig-growing areas of Japan (Kajitani and Masuya, 2011; Kajii et al., 2013).

In 2018, a Ceratocystis species was isolated from two neighbouring fig orchards in the Attica region of Greece. The affected trees showed symptoms of wilt and extensive crown defoliation, and some trees had died. The morphological characteristics of the isolated fungus were similar to those of C. ficicola (Tjamos et al., 2018). In 2019 and 2020, the same fungus, based on morphology, was also isolated from diseased fig trees at different localities on Euboea Island, where considerable damage was occurring in fig orchards.

The objective of the present study was to identify Ceratocystis species, having similar morphology to $C$. ficicola, found causing disease on F. carica in the two regions of Greece. This was achieved based on multilocus phylogenetic analyses and detailed observation of morphological characteristics of the fungus, including comparisons with the ex-type isolate of C. ficicola. Pathways of dispersal of the pathogen were also considered and the extent of damage to fig orchards in Greece is reported. Pathogenicity tests were also conducted with the fungus on plants of F. carica and Ficus benjamina $\mathrm{L}$.

\section{MATERIALS AND METHODS}

Sampling and fungus isolations

Field surveys for disease symptoms were conducted from April to early September, corresponding to the time of year that fig trees retain full foliage. In the fig orchards of the Markopoulo Mesogaias municipality in East Attica, surveys took place in 2018 and 2019, and in the Istiaia-Aidipsos municipality on the Euboea Island, in 2019 and 2020 (Table 1). These two regions are more than $200 \mathrm{~km}$ apart.

Trees with symptoms including crown defoliation and leaf wilt were sampled. The lower parts of the main stems were examined for the presence of necrotic bark, which was then removed to expose diseased cambial tissues and discoloured wood (Figure 1C-E). Samples of stained wood were then cut from the lesions using a surface-disinfected chisel. Some of the young plants were uprooted; the root systems examined for disease symptoms, and these were collected for laboratory examination. Soil samples were also collected from a depth of $15-20 \mathrm{~cm}$ near the bases of symptomatic trees from most of the surveyed orchards.

For isolation of fungi, PARPH V8 agar medium was used (containing $5 \%$ clarified V8 juice, $5 \mu \mathrm{g} \mathrm{mL}^{-1}$ pimaricin, $250 \mu \mathrm{g} \mathrm{mL}^{-1}$ ampicillin, $10 \mu \mathrm{g} \mathrm{mL}^{-1}$ rifamycin, 50 $\mu \mathrm{g} \mathrm{mL} \mathrm{m}^{-1} \mathrm{PCNB}$, and $50 \mu \mathrm{g} \mathrm{mL}^{-1}$ hymexazol). This selective medium is widely used for the isolation of Phytophthora species (Ferguson and Jeffers, 1999) but was also effective for the isolation of Ceratocystis species.

Table 1. Occurrence of Ceratocystis ficicola in fig orchards of Greece.

\begin{tabular}{|c|c|c|c|c|}
\hline Locality & Fig cultivar & Dates investigated & Number of orchards & Number of trees sampled \\
\hline \multicolumn{5}{|l|}{ Regional Unit of East Attica } \\
\hline \multirow{3}{*}{$\begin{array}{l}\text { Municipality of Markopoulo } \\
\text { Mesogaias }\end{array}$} & Vasilika honey-white & May 2018 & 1 & 4 \\
\hline & Vasilika black & May 2018 & 1 & 2 \\
\hline & Vasilika honey-white & April 2019 & 1 & 2 \\
\hline \multicolumn{5}{|l|}{ Euboea Island } \\
\hline \multicolumn{5}{|l|}{ Municipality of Istiaia-Aidipsos } \\
\hline Avgaria village & Smyrna & April, September 2019 & 2 & 3 \\
\hline Taxiarchis village & Smyrna & September 2019 & 1 & 2 \\
\hline Oreoi village & Smyrna & September 2020 & 2 & 4 \\
\hline Kastaniotissa village & Smyrna & September 2020 & 2 & 3 \\
\hline
\end{tabular}




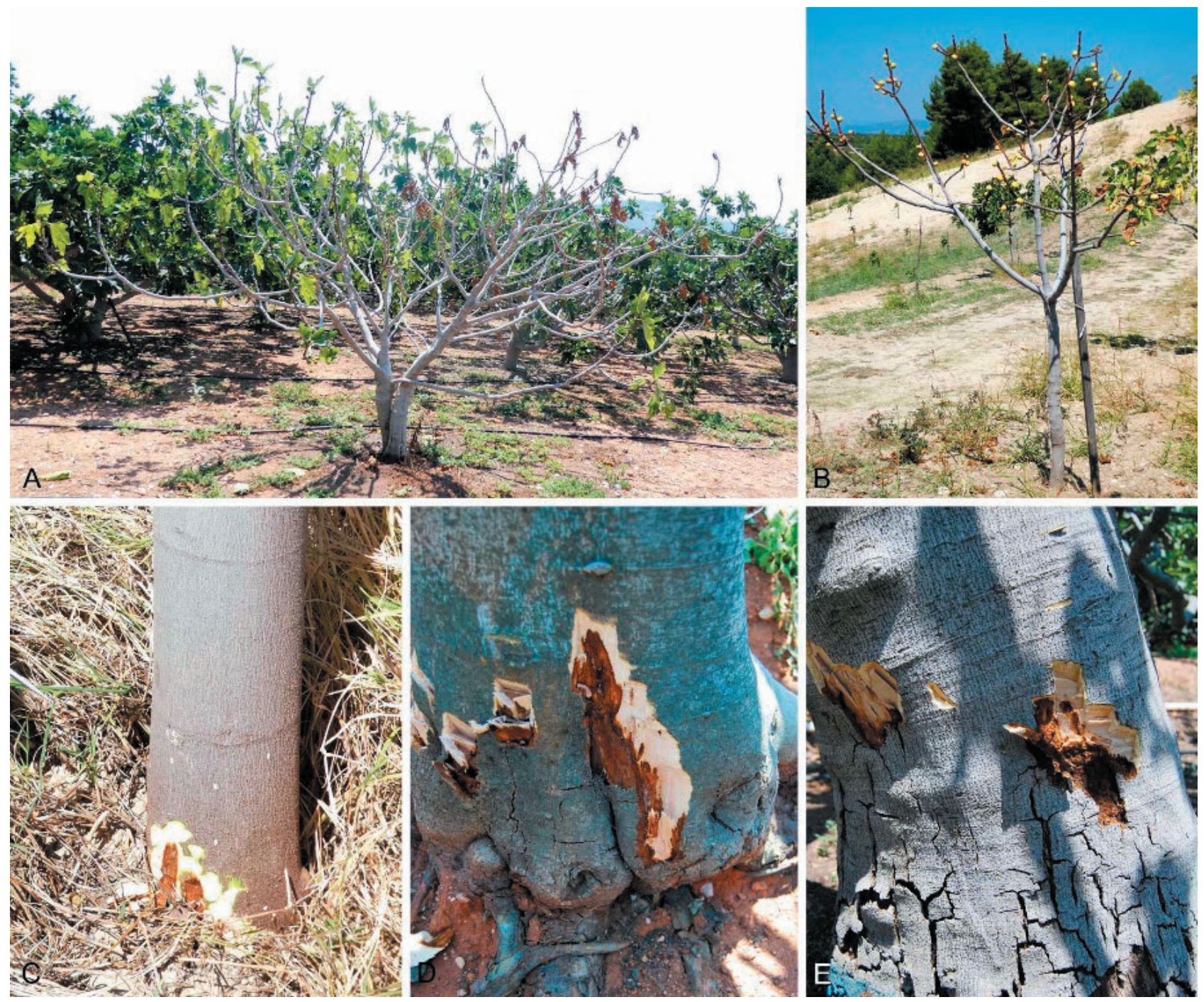

Figure 1. Field images of infected fig trees. A, infected mature tree of Vasilika honey-white cultivar with symptoms of leaf wilt and defoliation; B, infected young tree of Smyrna cultivar defoliated at the end of summer, with some of the unripe fruit still on the tree; and C, D and E, cankers at the bases of Ficus carica trees, with extensive wood staining under the dead bark.

Direct isolation from wood samples was performed after they had been surface-disinfested with $70 \%$ ethanol and air dried in a laminar flow cabinet. Small pieces of stained wood were aseptically removed from the samples with a sterile scalpel and transferred to Petri dishes containing PARPH V8A medium.

A carrot baiting method was also used for a sub-set of samples. Small pieces of stained wood were placed between two slices (each $5 \mathrm{~mm}$ thick) of carrot root, as described by Moller and De Vay (1968). The carrot baits were then placed in empty Petri dishes with moistened filter paper and incubated for $7-10 \mathrm{~d}$ at $25^{\circ} \mathrm{C}$. The carrot discs were subsequently examined for the presence of ascomata under a dissecting microscope, and when these were present, masses of ascospores were transferred to PARPH V8A medium.

Isolations from soil samples were performed using a modification of the trapping technique described by Grosclaude et al. (1988) for Ceratocystis platani (Walter) Engelbrecht and Harrington. Soil samples (40-50 g) were placed in $250 \mathrm{~mL}$ capacity conical flasks, which were filled with $200 \mathrm{~mL}$ of sterile deionized water. Freshly cut twigs from fig trees (approx. $10 \mathrm{~cm}$ long and 6-10 $\mathrm{mm}$ in diameter) with the bark removed were placed in the flasks. Air was continuously pumped into the flasks through a Pasteur pipette, using an aquarium pump (Aqua-Air AP4, Interpet). The flasks were incubated at room temperature $\left(23-25^{\circ} \mathrm{C}\right)$. After $7-10$ days, the 
twigs were examined under a dissecting microscope for the presence of ascomata and, where present, masses of ascospores were aseptically transferred to PARPH V8A medium. In some cases, this trapping technique was also used with pieces of infected wood in the flasks rather than soil. In all cases, resulting, agar medium colonies having Ceratocystis morphology were sub-cultured onto V8A medium.

\section{Growth in culture}

Growth rates of fungal cultures were determined on $10 \%$ V8A at different temperatures from 10 to $40^{\circ} \mathrm{C}$ at $5^{\circ} \mathrm{C}$ intervals. Two measurements of colony diameters were made perpendicular to each other on each culture plate after 7 and $14 \mathrm{~d}$ incubation at $25^{\circ} \mathrm{C}$.

Measurements of fungal structures were made from 7 to $10 \mathrm{~d}$ old pure cultures on V8A and malt extract agar (MEA) with fungal structures mounted in water or $85 \%$ lactic acid. A Zeiss Axioskop light microscope and SC30 camera (Olympus) or a Nikon Eclipse $\mathrm{N} i$ microscope and DS-Ri2 camera (Nikon) were used to capture images and to take measurements. Ascomata were examined at 50x or 100x magnification and the conidia and ascospores at $400 \times$ or $1000 \times$. For each of the two isolates from Greece (CMW 56935 and CMW 54794), the dimensions of 50 conidia of each type were measured.
Besides the isolates from Greece, the ex-holotype culture of C. ficicola from Japan (MAFF $625119=$ CMW 38543) was also examined.

\section{DNA extraction, sequencing and phylogenetic analyses}

To confirm the identity of the Ceratocystis species isolated from infected fig trees, two cultures from infected wood and two from the soil baiting (Table 2) were subjected to DNA sequencing. Mycelium from the cultures grown on 2\% MEA for approx. 2 weeks was scraped from the surfaces of the agar culture plates and DNA was extracted using the Fungal DNA MiniPrep kit (Zymo Research).

Three gene regions were PCR-amplified and sequenced. Primers RPB2-5Fb and RPB2-7Rb were used to amplify the second largest subunit of the RNA polymerase II (rpb2) (Fourie et al., 2015), primers $\beta$ tla and $\beta$ t $1 \mathrm{~b}$ (Glass and Donaldson, 1995) to amplify the $\beta$-tubulin 1 (bt1) region, and primers EF1-728F and EF1986R (Jacobs et al., 2004) for the Translation Elongation Factor 1- $\alpha$ (tef1) gene region.

PCR reactions and conditions, including optimal $\mathrm{MgCl}_{2}$ concentrations and annealing temperature for the three gene regions, were carried out as described by Fourie et al. (2015), with an Expand-PCR programme of $96^{\circ} \mathrm{C}$ for $10 \mathrm{~min},\left(94^{\circ} \mathrm{C}\right.$ for $30 \mathrm{~s}$, primer specific anneal-

Table 2. Details of the Ceratocystis ficicola isolates from Japan and Greece analysed in the present study.

\begin{tabular}{|c|c|c|c|c|c|c|c|c|}
\hline \multirow{2}{*}{ Species $^{1}$} & \multirow{2}{*}{ Isolate $\mathrm{No}^{2}$} & \multirow{2}{*}{ Substrate } & \multirow{2}{*}{ Country } & \multirow{2}{*}{ Locality } & \multirow{2}{*}{$\begin{array}{c}\text { Year } \\
\text { collected }\end{array}$} & \multicolumn{3}{|c|}{ GenBank accession numbers } \\
\hline & & & & & & bt1 & tef1 & $\mathrm{rpb} 2$ \\
\hline C. ficicola ${ }^{\mathrm{T}}$ & $\begin{array}{c}\text { MycoBank 518749; CMW } \\
\text { 38543; BPI 843724, MAFF } \\
625119\end{array}$ & Ficus carica & Japan & Fukuoka Prefecture & 1990 & KY685077 & KY316544 & KY685082 \\
\hline C. ficicola & CMW 38544; NCF0801 & Ficus carica & Japan & Fukuoka Prefecture & 1991 & KY685078 & KY685079 & KY685083 \\
\hline C. ficicola & CMW 54793; FCE-1 & $\begin{array}{c}\text { Ficus carica cultivar } \\
\text { Smyrna }\end{array}$ & Greece & $\begin{array}{l}\text { Istiaia-Aidipsos, } \\
\text { Avgaria village }\end{array}$ & 2019 & $\begin{array}{l}\text { Same as } \\
\text { KY685077 }\end{array}$ & $\begin{array}{l}\text { Same as } \\
\text { KY316544 }\end{array}$ & $\begin{array}{l}\text { Same as } \\
\text { KY685082 }\end{array}$ \\
\hline C. ficicola & CMW 54794; FCE-2 & $\begin{array}{l}\text { Soil under infected } \\
\text { Ficus carica cultivar } \\
\text { Smyrna }\end{array}$ & Greece & $\begin{array}{l}\text { Istiaia-Aidipsos, } \\
\text { Avgaria village }\end{array}$ & 2019 & $\begin{array}{l}\text { Same as } \\
\text { KY685077 }\end{array}$ & $\begin{array}{l}\text { Same as } \\
\text { KY316544 }\end{array}$ & $\begin{array}{c}\text { Same as } \\
\text { KY685082 }\end{array}$ \\
\hline C. ficicola & CMW 54795; FCE-4 & $\begin{array}{l}\text { Soil under infected } \\
\text { Ficus carica cultivar } \\
\text { Smyrna }\end{array}$ & Greece & $\begin{array}{l}\text { Istiaia-Aidipsos, } \\
\text { Avgaria village }\end{array}$ & 2019 & $\begin{array}{l}\text { Same as } \\
\text { KY685077 }\end{array}$ & $\begin{array}{c}\text { Same as } \\
\text { KY316544 }\end{array}$ & $\begin{array}{c}\text { Same as } \\
\text { KY685082 }\end{array}$ \\
\hline C. ficicola & CMW 54796; FCM-1 & $\begin{array}{l}\text { Ficus carica cultivar } \\
\text { Vassilika honey } \\
\text { white }\end{array}$ & Greece & $\begin{array}{l}\text { Municipality } \\
\text { of Markopoulo } \\
\text { Mesogaias }\end{array}$ & 2018 & $\begin{array}{l}\text { Same as } \\
\text { KY685077 }\end{array}$ & $\begin{array}{c}\text { Same as } \\
\text { KY316544 }\end{array}$ & $\begin{array}{c}\text { Same as } \\
\text { KY685082 }\end{array}$ \\
\hline
\end{tabular}

${ }^{1} \mathrm{~T}$ = Ex-type material of Ceratocystis ficicola;

${ }^{2} \mathrm{CMW}=$ Culture collection of the Forestry and Agricultural Biotechnology Institute (FABI), University of Pretoria, South Africa; BPI = US National Fungus Collections, Beltsville, Maryland, USA; MAFF = Ministry of Agriculture, Forestry and Fisheries Culture Collection, Tsukuba, Ibaraki, Japan; FCE, FCM= Institute of Mediterranean Forest Ecosystems culture collection numbers 
ing temperature for $45 \mathrm{~s}, 72^{\circ} \mathrm{C}$ for $1 \mathrm{~min}$ ) for 10 cycles, $\left(94^{\circ} \mathrm{C}\right.$ for $30 \mathrm{~s}$, primer specific annealing temperature for $45 \mathrm{~s}, 72^{\circ} \mathrm{C}$ for $1 \mathrm{~min}+5 \mathrm{~s} / \mathrm{cycle}$ increase) for 30 cycles, and $72^{\circ} \mathrm{C}$ for $10 \mathrm{~min}$. All amplicons were purified using 6\% Sephadex G-50 columns (Sigma-Aldrich), were sequenced in both directions using the ABI PRISM ${ }^{\mathrm{TM}}$ Big DYE Terminator Cycle Sequencing Ready Reaction Kit (Applied BioSystems), and the products were run on an ABI 3100 Genetic Analyzer (Applied BioSystems, Thermo Fisher).

The forward and reverse sequence reads were assembled into contigs in CLC Bio Main workbench v.6 (CLC Bio, www.clcbio.com), and the consensus sequences generated were used in BLAST analyses against the NCBI GenBank database (NCBI; http://www.ncbi.nlm.nih.gov) to determine the closest similarity matches with authenticated Ceratocystis species.

Sequences were added to the combined $r b p 2, b t 1$ and tef1 Ceratocystis database obtained from Barnes et al. (2018) (TreeBASE No. S22005), with a focus on retaining all the Ceratocystis species in the Asian-Australian Clade (AAC) in the phylogenetic analyses. Ceratocystis albifundus was used as the outgroup taxon. Sequences were re-aligned using the online version of MAFFT v. 7 (http://mafft.cbrc.jp/alignment/server/). Maximum parsimony (MP) analyses performed in PAUP v. 4.0 (Swofford 2002) and Maximum likelihood (ML) analysis in RAxML (Stamatakis 2014) were carried out on the combined dataset with the same parameters used by Barnes et al. (2018).

\section{Inoculation tests}

Two isolates of C. ficicola collected from different localities were used for inoculation trials. One of these (CMW 56935) from the Attica region was used in the first test (2018) and the other (CMW 54794) from Euboea Island was used in the second test (2019). The isolates used in the inoculation tests were grown for 2 weeks at $25^{\circ} \mathrm{C}$ in Petri dishes containing V8A. For inoculations, a $3 \mathrm{~mm}$ diam. cork-borer was used to remove the bark from stems or branches of test trees (see below), and a mycelium plug of similar size was inserted into each wound which was then wrapped with Parafilm. Control plants were inoculated in the same way with sterile V8 agar plugs.

The two inoculation tests were carried out at the Institute of Mediterranean Forest Ecosystems in Athens, Greece. In the first test, 11 branches (diam. 1-4 cm) of a wild F. carica tree were inoculated in June 2018 with isolate CMW 56935. In the second test conducted in September 2019, a total of 13 F. carica saplings (1-2 years- old) of different size and grown in 7.5 L capacity pots, were inoculated with isolate CMW 54794. Stem diameters of these plants at the inoculation points was from 5 to $20 \mathrm{~mm}$. Non-inoculated control plants were not used in the first test, while in the second test six plants were inoculated with sterile V8 agar plugs.

In September 2019, inoculations were also performed on branches of two Ficus benjamina trees, in the same area with isolate CMW 54794. A total of 16 branches on the two trees were inoculated. A third $F$. benjamina tree was used as a control, by inoculating seven branches with sterile V8 agar plugs.

After inoculation, the plants were monitored regularly for expression of disease symptoms. In the first inoculation test (2018), the inoculated branches were harvested after 5 weeks. In the second test (2019), most of the plants were harvested 6 weeks after inoculation, although some of the plants displaying symptoms of wilt were harvested at an earlier time to allow for lesions to be measured. All inoculated stems and branches were sliced open vertically above and below the inoculation points, and the lengths of internal xylem staining were measured. Re-isolations from these lesions were made at different distances from the inoculation points, by aseptically transferring pieces of stained wood onto the selective V8A medium.

Statistical analyses were performed to compare the means of internal lesion lengths for the inoculations on $F$. carica and F. benjamina branches or stems of the $F$. carica sapling plants. In these comparisons, only the saplings of F. carica that were harvested after 6 weeks were included. A Shapiro-Wilk test was used to test normality of the data, and a Levene's test was used to assess equality of variances. A Kruskal-Wallis $\mathrm{H}$ test was then applied to compare the means of lesion lengths between F. carica and F. benjamina plants, followed by DunnBonferroni post hoc method.

\section{RESULTS}

\section{Disease symptoms and distribution}

In the Markopoulo Mesogaias municipality in East Attica, wilt of fig trees was detected at one location with orchards of mature fig trees (20-30 years-old) of the 'Vasilika honey-white' and 'Vasilika black' cultivars, distributed over approx. 10 ha (Table 1). In the IstiaiaAidipsos municipality, in the northern part of Euboea Island, the disease was found in fig orchards at four locations (villages) more than $10 \mathrm{~km}$ apart, on young as well as mature trees. All the wilt-affected trees on Euboea Island were of the 'Smyrna' cultivar (Table 1). 
Wilted mature trees were usually located in one part of each orchard, and the disease appeared to have spread to neighbouring fig trees. In some cases, more than one disease centre was observed. Infected mature trees of all three cultivars showed thinning and yellowing of the foliage, either on some of the branches or over the entire crowns (Figure 1A). In some trees, most of the leaves had dropped by the end of summer, while some of the unripe fruits were retained on the trees indicating rapid death (Figure 1B). In many of the affected mature trees, complete defoliation was observed by the end of the summer, although full foliage had been present on these trees early in the spring. The affected trees eventually died, and in many cases, where dead trees had been replaced with new young plants; these were also dying within 1 to 2 years after replacement.

On mature trees, extensive bark cankers were observed at the bases of the trunks. Necrotic dark brown sapwood was obvious after removal of the bark in the lower part of the trunks (Figure 1C-E), and these lesions extended upwards. Necrotic roots were also observed on affected trees. In some symptomatic young (2-3 yearsold) trees, wood staining was not always present at the trunk bases, although in these cases necrotic roots were observed. Wood staining was not found on the branches of wilted trees with chlorotic leaves, or on defoliated trees. Infestations by wood boring insects were not observed on any of the wilted fig trees examined.

In a newly planted 6 ha orchard on Euboea Island, 3 years after planting, approx. $40-50 \%$ of the trees were dead or dying with evident disease symptoms. This land had not previously been used for fig tree cultivation.

\section{Fungus isolations}

A Ceratocystis species was consistently isolated directly from stained fig tree wood on the selective PARPH V8A medium. The fungus was also isolated on plain V8A, but in most of these cases it was overgrown by saprotrophic fungi. On selective medium, colonies were suppressed and scarcely formed ascomata, but they resumed normal growth when transferred to plain V8A medium and ascomata developed after 7-10 d.

The Ceratocystis species was also isolated using the carrot baiting technique, but in many cases the carrots were contaminated with bacteria and isolations were inconsistent using this technique. The trapping technique with fig twigs as baits was effective for isolating the Ceratocystis species from soil and from wood samples. For twig baiting, the fungus had colonized the twigs and formed ascomata (Figure 2A) after 7-10 d, at the water level. The fungus was easily isolated from ascospore masses transferred to selective medium. In a few cases, it was not possible to isolate the fungus from wood samples taken from symptomatic trees, especially where these trees had died, but the fungus was readily isolated from soil samples collected near the bases of these trees using the twig baiting technique.

\section{Fungus morphology}

Colonies in V8A, after 7-10 d in culture, were circular with slightly undulate margins and were dark olivaceous green. The optimum growth temperature was $25^{\circ} \mathrm{C}$, with a radial growth of $20-23 \mathrm{~mm}$ week $^{-1}$. The fungus grew well at $30^{\circ} \mathrm{C}$ but no growth was observed at 35 or $40^{\circ} \mathrm{C}$. When the cultures were transferred to $25^{\circ} \mathrm{C}$ after 2 weeks incubation at $35^{\circ} \mathrm{C}$, the colonies resumed normal growth, but incubation for 2 weeks at $40^{\circ} \mathrm{C}$ killed the fungus and no growth was observed on the plates after transferring these to $25^{\circ} \mathrm{C}$.

Black ascomata (Figure 2A, B) were observed after 7-10 d incubation on V8A, and were partially embedded in the agar. These measured $400-600 \mu \mathrm{m}$ diam. and had globose bases and long necks (1150-2200 $\mu \mathrm{m}$ long). They had ostiolar hyphae at the tips of the necks (Figure 2C) which were 180-300 $\mu \mathrm{m}$ long. Ascospores exuding from the tips of the ascomata necks formed sticky masses of creamy colour (Figure 2A). Ascospores were one-celled, ellipsoidal in top view, measured 5-7 $\times 4-5 \mu \mathrm{m}$, with the characteristic "bowler-hat" shape typical of Ceratocystis spp. (Figure 2D). The fungus produced abundant cylindrical endoconidia $(12-40 \times 4-7 \mu \mathrm{m})$ with rounded apices, and these varied slightly as bulged to straight, from less to more round apices (Figure 2F, G). The conidia were extruded in chains from tubular conidiogenous cells (Figure 2H). Aleurioconidia (Figure 2E) were formed singly or in short chains on short conidiophores, and these were ovoid to subglobose $(9-13 \times 7-12 \mu \mathrm{m})$, pigmented and thick-walled. Doliform endoconidia were not observed.

Morphological characteristics of the Greek isolates were identical to those of the Japanese isolate (exholotype MAFF $625119=$ CMW 38543), except that the dimensions of the endoconidia were different. The Japanese isolate had cylindrical endoconidia with dimensions of 5-9.5 $\times 4.5-8 \mu \mathrm{m}$, whereas those made in the present study were $12-40 \times 4-7 \mu \mathrm{m}$.

\section{Sequencing and phylogenetic analyses}

Amplicons of the $r p b 2, b t 1$ and tef 1 gene regions produced fragments of approx. 1123, 592 and $754 \mathrm{bp}$, 

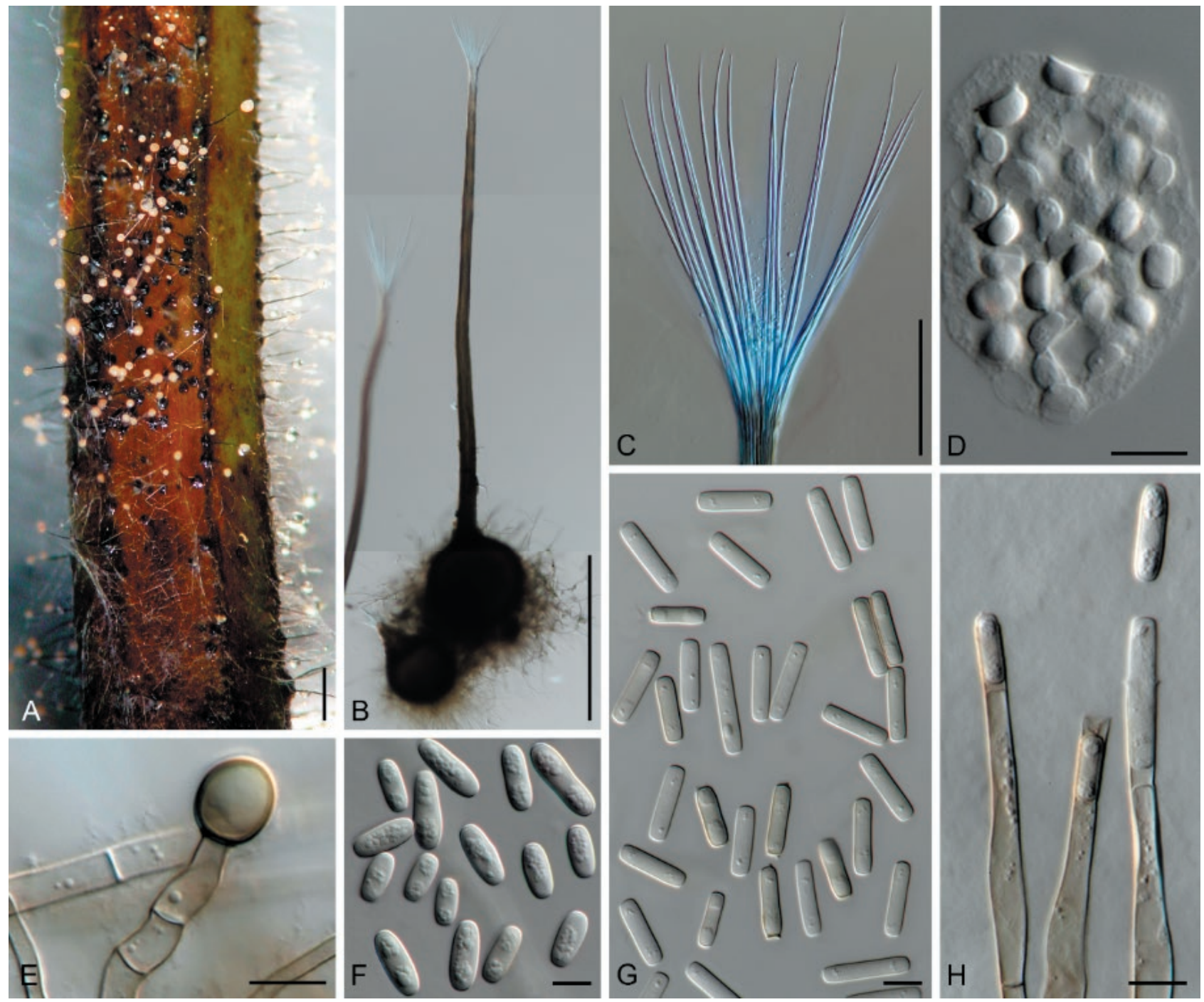

Figure 2. Microscopic features of Ceratocystis ficicola. A, ascomata on a twig bait; B, ascoma; C, ostiolar hyphae; D, ascospores; E, an aleurioconidium; $F$ and $G$, cylindrical endoconidia; $H$, phialides. Scale bars: $A=1.5 \mathrm{~mm} ; \mathrm{B}=500 \mu \mathrm{m} ; \mathrm{C}=100 \mu \mathrm{m} ; \mathrm{D}$ to $\mathrm{H}=10 \mu \mathrm{m}$.

respectively. For each of the three gene regions, the sequences for all four isolates were $100 \%$ identical to each other. Blast searches against the NCBI GenBank database resulted in $100 \%$ identity matches to C. ficicola ex-type isolate from Japan [Mycobank MB518749, CMW 38543 for rpb2 (KY685082), bt1 (KY685077) and tef1 (KY316544) gene regions (Table 2)].

The combined dataset (rpb2, bt1 and tef1) of the sequences used for the phylogenetic analyses consisted of 2127 aligned characters. MP analyses resulted in eight most parsimonious trees with $\mathrm{TL}=299, \mathrm{CI}=0.863, \mathrm{RI}=$ 0.945 and $\mathrm{RC}=0.815$, with 238 parsimony-informative characters and six uninformative characters. For the ML analyses, using GTR-GAMMA as the best fit model, the log-likelihood of the most likely tree obtained was -5139.12. MP and ML analyses placed the isolates from Greece, collected from infected F. carica, and those obtained from the soil, in the same clade as those of $C$. ficicola from Japan with 100\% bootstrap support (Figure 3). These isolates form part of the Asian Australian Clade (ACC) of Ceratocystis, as defined by Li et al. (2017).

\section{Inoculation tests}

All the plants of F. carica and F. benjamina inoculated with C. ficicola developed symptoms of infections (Figure 4), while no symptoms were observed on any 


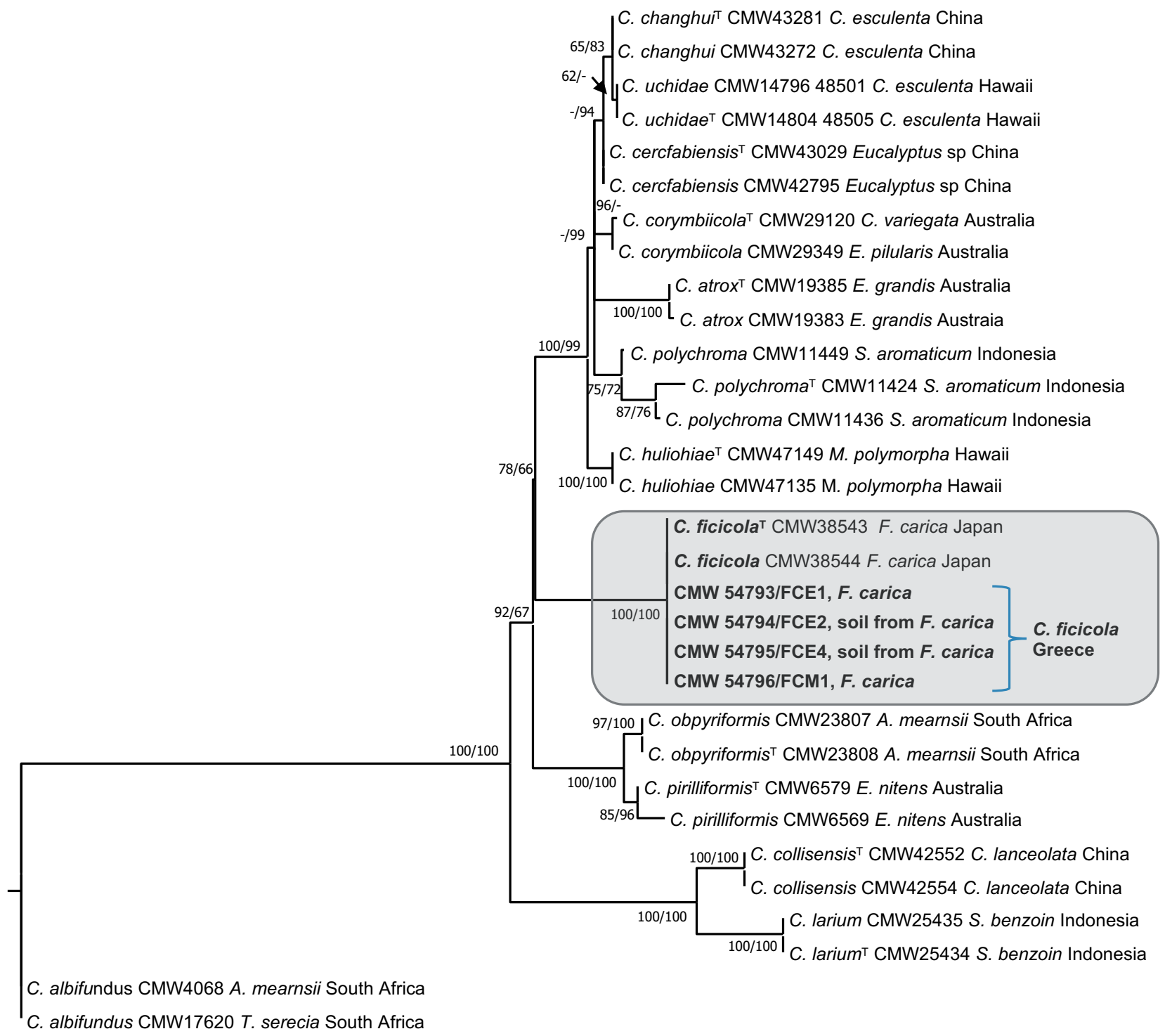

0.020

Figure 3. Phylogenetic placement of the isolates from Greece with Ceratocystis ficicola from Japan in the Asian-Australian Ceratocystis Clade. The ML phylogeny, constructed from the combined regions of the $r p b 2, b t 1$ and tefl gene sequences, is presented with MP and ML bootstrap values $>60 \%$ indicated on the branch nodes. T indicates ex-type representatives of each species. Ceratocystis albifundus was used as the outgroup.

of the control plants. Lesions on the inoculated plants included necrotic bark around the inoculation point (Figure 4B), which, in some cases, was evident as early as 2 weeks after inoculation. Exposure of the cambium in stems showed brown-coloured streaked discolouration of the woody tissues, extending longitudinally in the xylem beyond the necrotic bark (Figure 4D, E).
Branch inoculations on Ficus carica

The internal lesions associated with the stained wood on the F. carica branches inoculated in 2018, and measured after 5 weeks, extended up to $12 \mathrm{~cm}$ from the inoculation points. The lesion lengths were $10-23 \mathrm{~cm}($ mean $=14.2 \mathrm{~cm})$. 


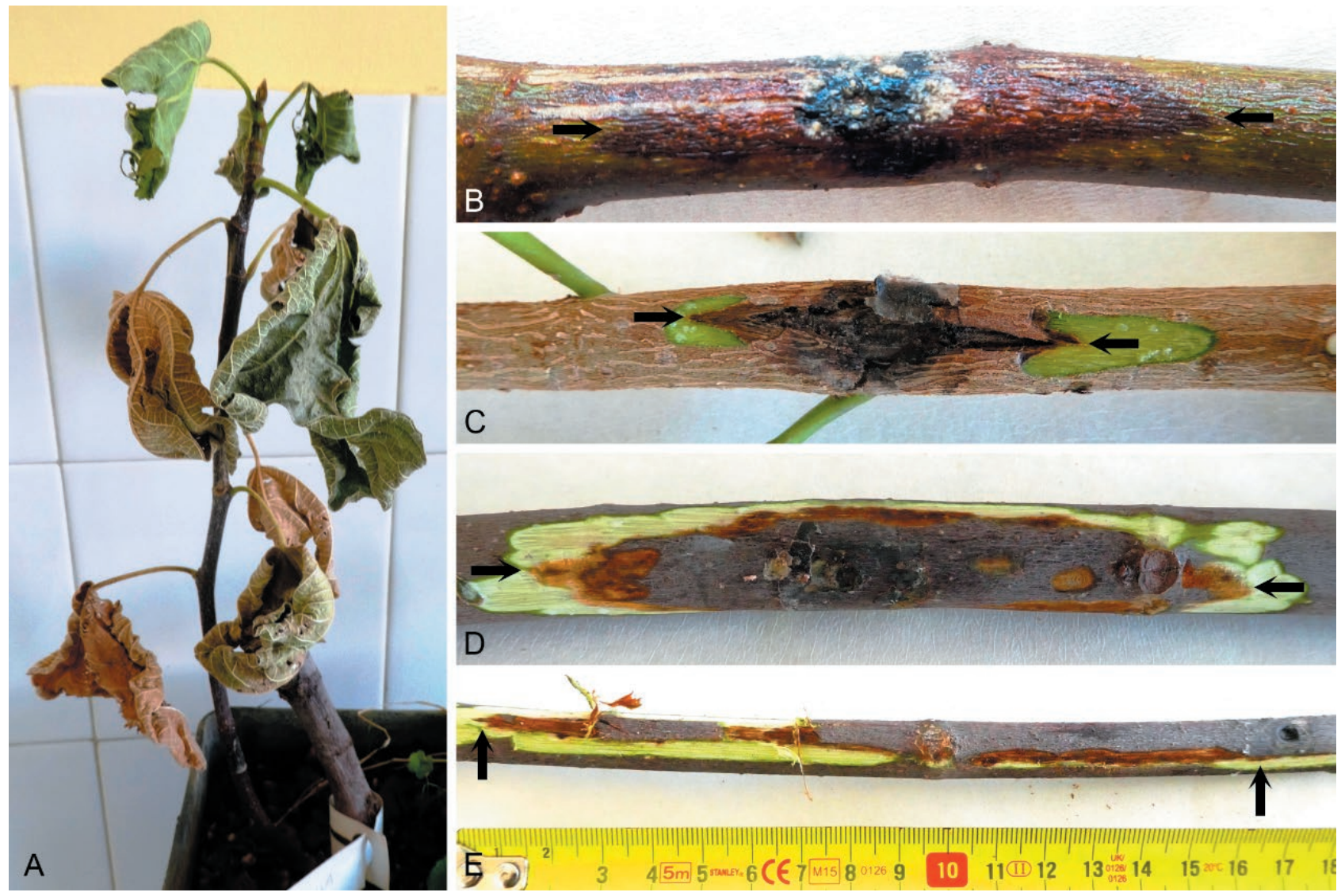

Figure 4. Inoculations with Ceratocystis ficicola. A, Ficus carica symptoms of leaf wilt 6 weeks after inoculation; B, canker formed on a branch twig of F. carica 5 weeks after inoculation; C, canker formed on a branch twig of F. benjamina 6 weeks after inoculation; D and E, main stem of a F. carica sapling with xylem discolouration extending longitudinally beyond the necrotic bark 6 weeks after inoculation. Arrows in $\mathrm{E}$ show the edges of the lesion.

Inoculations on Ficus carica saplings

Three of the F. carica saplings inoculated in 2019 that had small diameters $(57 \mathrm{~mm})$, showed stem girdling and symptoms of wilt 2 weeks after inoculation. For these three plants, the lesions were $6-12 \mathrm{~cm}$ long. For the other ten saplings, the internal lesion lengths were up to 21 $\mathrm{cm}$ long at 6 weeks after inoculation. The total lengths of the stained wood associated with these inoculations was from $2.6-37.8 \mathrm{~cm}($ mean $=12.9 \mathrm{~cm})($ Figure 5$)$.

\section{Branch inoculations on Ficus benjamina}

Inoculated-branches developed necrotic lesions around the inoculation sites (Figure 4C). On this host, wood staining was very limited, extending only $0.8-1.5$ $\mathrm{cm}$ from the inoculation points with total length 1.4-3 $\mathrm{cm}$ (mean $=2.17 \mathrm{~cm})$. Symptoms of wilt were not evident on branches 6 weeks after inoculation.
Mean lesion length $(\mathrm{cm})$

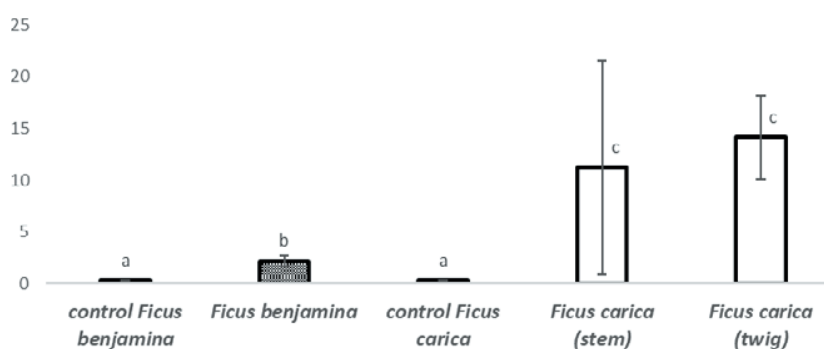

Figure 5. Mean internal lesion lengths $(\mathrm{cm})$, after inoculation of Ficus carica sapling stems and branch twigs, or F. benjamina branch twigs, with Ceratocystis ficicola. Columns accompanied by standard deviations of means, and those accompanied by the same letters are not significantly different $(P \leq 0.05)$

There were no statistically significant differences in the mean internal lesion lengths between F. carica saplings (stems) and branches (twigs) in the two experiments, according to Kruskal-Wallis $\mathrm{H}$ test and Dunn- 
Bonferroni post hoc method $(P \leq 0.05)$ (Figure 5). In contrast, the mean lesion lengths on the $F$. benjamina branches differed significantly from both of the F. carica inoculations. There were also significant differences between lesion lengths for the control plants and those inoculated with the C. ficicola on both hosts (Figure 5). For F. carica, wood discolouration was limited to approx. $3 \mathrm{~mm}$ around the inoculation sites.

The inoculated fungus was consistently re-isolated from stained wood from $F$. carica and F. benjamina plants, and at different distances (up to $17 \mathrm{~cm}$ ) from the inoculation points. The re-isolated fungus had the typical morphology of the inoculated fungus. The fungus could not be isolated from plants inoculated as experimental controls.

\section{DISCUSSION}

This study has provided clear evidence for the presence of $C$. ficicola in fig orchards in two separate regions (Attica and Euboea Island) of Greece. These two areas separated by large distance. This is the first detailed report of the presence of this fungus outside of Japan, in this case also supported by morphological and DNA sequence comparisons. This study also included inoculation trials that confirmed the pathogenicity of Greek isolates of C. ficicola.

A similar disease to that caused by C. ficicola in Japan and Greece has been reported in Brazil on cultivated fig trees. In that case the pathogen was reported as Ceratocystis fimbriata Ellis and Halsted sensu lato (Pasura and Harrington, 2004). Kajitani and Masuya (2011) showed that C. ficicola is different to the Ceratocystis species from fig trees in Brazil, based on morphological differences and ITS sequences. The distinct nature of the fungus killing fig trees in Brazil and Japan was also confirmed by Harrington et al. (2011). Results of the present study based on morphological comparisons and DNA sequence data for three gene regions also confirmed that C. ficicola from Greece is in the Asian-Australian clade of Ceratocystis ( $\mathrm{Li}$ et al., 2017). In contrast, isolates from fig trees in Brazil form part of the Latin American Clade (Harrington et al., 2011).

Observations in the present study agree with those of Kajitani and Masuya (2011), confirming that C. ficicola has morphology that is distinct from other species of Ceratocystis. This is relevant as many species of Ceratocystis, as defined by De Beer et al. (2014), cannot easily be distinguished based on morphology. The most characteristic structures in C. ficicola that distinguish it from other Ceratocystis species are the large ascomata with very long necks $(>2000 \mu \mathrm{m})$. Ascospores are very similar in shape and size to those of Ceratocystis fimbriata sensu stricto (Marincowitz et al., 2020). Doliform endoconidia were not observed in the present study, and these were also absent from observations of Kajitani and Masuya (2011). However, there was a difference in the size of the cylindrical endoconidia in the present study isolates compared with those described by Kajitani and Masuya (2011). This was confirmed in comparisons of the Greek isolates and the Japanese ex-holotype isolate (CMW 38543) made in the present study.

In Japan, the disease of fig caused by C. ficicola is commonly referred to as "Ceratocystis canker", but Kajii et al. (2013) stated that the disease is more typical of vascular wilt. The pathogen invades the roots and the main stems of host plants, causing xylem dysfunction and wilt symptoms on infected fig trees. In cross sections of main stems, dark brown radial discolouration of the sapwood tissues was evident at the bases of affected trees, extending upwards and downwards to the roots (Kajii et al., 2013). Consistent with the view of Kajii et al. (2013) that infection by C. ficicola should be defined as a wilt disease, Morita et al. (2016) and Sumida et al. (2016) in inoculation studies on mature fig trees, as well as young seedlings, reported that xylem discolourations were correlated with xylem dysfunction. The water supply to leaves decreased when infection progressed causing leaf wilting and extensive xylem dysfunction leading to plant death.

Ceratocystis ficicola also kills host cambium and the bark tissues causing cankers, which were present at the bases of the main stems on most symptomatic trees in Greece. In our surveys, wood discolouration was not evident in the branches of trees displaying wilt of the leaves, and similar observations were made in Japan by Kajii et al. (2013). However, the inoculated branch twigs in our experiments developed cankers and extensive wood discoloration. Overall, these symptoms are similar to those of many other tree diseases caused by Ceratocystis species, and the disease is best described as canker-wilt (Tsopelas et al., 2017; Nasution et al., 2019).

In the present study, inoculation experiments, showed that $F$. benjamina and not only $F$. carica plants can become infected with C. ficicola. However, this species was less susceptible to the pathogen than F. carica. In Japan, Ficus erecta Thunb., which is an indigenous species, has been proven resistant to C. ficicola and has been used in breeding programmes to develop resistant fig tree rootstocks (Yakushiji et al., 2019).

In several studies carried out in Japan, it has been shown that $C$. ficicola is a soil-borne pathogen. It has also been suggested that the fungus persists in the soil as thickwalled aleurioconidia, and newly planted trees in contami- 
nated soil are soon infected by the pathogen (Kajii et al., 2013; Yakushiji et al., 2019). Our field observations, in both regions of Greece considered, also suggest soil-borne disease problems, where trees were planted to replace those that had died also became infected. We consistently isolated C. ficicola from soils associated with dying trees.

Detection of C. ficicola in the soil at an early stage will be important for pathogen detection and application of canker-wilt control strategies. In the present study, using twig baiting, the fungus was readily isolated from soil, even in cases where the pathogen could not be directly isolated from wood samples from nearby symptomatic trees. This baiting method was originally described by Grosclaude et al. (1988) for detection and isolation of Ceratocystis platani, which causes the canker stain of plane trees (Platanus). The method was also successfully used to isolate C. platani from adult Platypus cylindrus Fab. beetles, a vector of C. platani (Soulioti et al., 2015). The present study is the first to use baiting technique to isolate C. ficicola from soil and wood samples.

According to Kajitani and Masuya (2011), the dispersal biology of $C$. ficicola is not fully understood. One of the suggested pathways of disease spread in Japan was with infected propagation material (Kajii et al., 2013). This was also evident in one of the orchards examined on Euboea Island. The pathogen was widespread in a new plantation over an area of 6 ha, 3 years after the fig trees had been planted. Since there was no previous use of this land for fig cultivation, the most probable means of pathogen dissemination over such a short period would be with infected nursery stock.

Every effort should be made to avoid further spread of C. ficicola with planting material and via contaminated soil. This is a probable pathway for introduction and spread of the pathogen into other areas and countries. The pathogen can survive in soil associated with plants for planting, when symptoms are not evident. While nursery stock should be carefully examined for the presence of $C$. ficicola, disease symptoms may not be always evident, especially during winter when new plants are being established. This problem is exacerbated with fig trees having no foliage during this period, and infected plants may escape the attention during inspections.

Ceratocystis ficicola may also spread with tractors used for ploughing that move infested soil and wood debris within or between orchards. Deep ploughing also causes root wounding, allowing pathogen infection sites. The use of infested ploughing machinery is likely to be a major pathway for pathogen dissemination in the fig orchards of Euboea Island. A major pathway of disease spread for C. platani in many areas of Europe has been from terracing machinery that transmit the pathogen over short and long distances (Tsopelas et al., 2017). Some Ceratocystis species can also survive for long periods as aleurioconidia in infected wood. This spore form was also observed by Kajii et al., (2013) in the vessel elements of fig trees infected with $C$. ficicola. Contaminated pruning and cutting tools may therefore be involved in the spread of the pathogen to healthy trees. Precautionary measures, including disinfestation of pruning tools and the machinery used in fig orchards have been recommended to avoid further spread of C. ficicola in Greece.

Ambrosia beetles (Euwallacea interjectus Blandford) have been suggested as possible vectors of $C$. ficicola in Japan. These insects also contribute to expansion of the fungus in sapwood of infected trees (Kajii et al., 2013). The frass produced by the insects may also disseminate the pathogen, as with other Ceratocystis species (Harrington, 2013; Tsopelas et al., 2017). Frass can be dispersed by wind, rain splash or running water over short distances, and can contaminate soil or initiate new infections in pruning wounds (Harrington, 2013). In Greece, infestation by wood boring insects in C. ficicola-infected fig trees has not been observed. However, future surveys should include careful inspection for the presence of such insects. The ambrosia beetle Platypus cylindrus has been reported in Greece to attack Platanus orientalis trees already infected by C. platani, and this insect may be involved in the spread of that pathogen (Soulioti et al., 2015).

The origin of C. ficicola is unknown. Kajitani and Masuya (2011) have suggested two possibilities; one that the fungus is invasive in Japan, or alternatively, that it is native to that country and has, over time, come into contact with the highly susceptible F. carica. All evidence emerging from the present study indicates that C. ficicola is an alien invasive pathogen in Greece. This because F. carica has been cultivated in Greece since ancient times, but canker-wilt has only been detected in recent years and at a small scale. An important question remains as to how the pathogen was introduced into this country, either from Japan or from another source in the Mediterranean region where it is yet to be detected.

Ceratocystis ficicola causes a very important disease of fig trees in Japan, resulting in severe outbreaks of canker-wilt (Kajitani and Masuya, 2011; Yakushiji et al., 2019). The presence of the pathogen in Greece is particularly relevant. Fig is a very important crop in Mediterranean countries, because it is adapted to the dry climatic conditions of the region. About $70 \%$ of total world fig production occurs in Mediterranean countries (Flaishman et al., 2008). Consequently, the disease could result in severe loses if the pathogen were to be disseminated to other countries, such as Turkey, Egypt or Morocco where fig production is also important. 


\section{ACKNOWLEDGEMENTS}

The authors thank Vassilios Bournakas, agronomist in Euboea Island, for valuable help during the field surveys of this region, and Kira Lynn for technical assistance. Dr Hayato Masuya, (Forestry and Forest Products Research Institute, Japan) supplied the ex-type culture of C. ficicola from Japan. We acknowledge the Department of Science and Technology/National Research Foundation Center of Excellence in Plant Health Biotechnology, South Africa for financial support.

\section{LITERATURE CITED}

Barnes I., Fourie A., Wingfield M.J., Harrington T.C., McNew D.L., ... Keith L.M., 2018. New Ceratocystis species associated with rapid death of Metrosideros polymorpha in Hawaii. Persoonia 40: 154-181. https://doi.org/10.3767/persoonia.2018.40.07

Condit I.J., 1955. Fig varieties: A monograph. Hilgardia, 23: $323-538$.

De Beer Z.W., Duong T.A., Barnes I., Wingfield B.D., Wingfield M.J., 2014. Redefining Ceratocystis and allied genera. Studies in Mycology 79: 187-219. https://doi.org/10.1016/j.simyco.2014.10.001

FAO, 2019. The FAO statistical database-agriculture. Available at: http://www.fao.org/faostat/en/\#data/QC. Accessed March 4, 2021.

Ferguson A.J., Jeffers S.N., 1999. Detecting multiple species of Phytophthora in container mixes from ornamental crop nurseries. Plant Disease 83: 1129-1136.

Fourie A., Wingfield M.J., Wingfield B.D., Barnes I., 2015. Molecular markers delimit cryptic species in Ceratocystis sensu stricto. Mycological Progress 14: 1020. https://doi.org/10.1007/s11557-014-1020-0

Flaishman M., Rodov V., Stover E., 2008. The Fig: Botany, Horticulture, and Breeding. Horticultural Reviews 34: 113-197. https://doi.org/10.1002/9780470380147.ch2

Glass N.L., Donaldson G.C., 1995. Development of primer sets designed for use with the PCR to amplify conserved genes from filamentous Ascomycetes. Applied and Environmental Microbiology 61: 1323-1330. https://doi.org/10.1128/AEM.61.4.1323-1330.1995

Grosclaude C., Olivier R., Pizzuto J.C., Romiti C., Madec S., 1988. Détection par piégeage du Ceratocystis fimbriata $\mathrm{f}$. platani. Application à l'étude de la persistance du parasite dans du bois infecté. European Journal of Forest Pathology 18: 385-390.

Harrington T.C., 2013. Ceratocystis diseases. In: Gonthier P, Nicolotti G Eds. Infectious Forest Diseases. UK: CABI Publishing, 230-255.
Harrington T.C., Thorpe D.J., Alfenas A.C., 2011. Genetic variation and variation in aggressiveness to native and exotic hosts among Brazilian populations of Ceratocystis fimbriata. Phytopathology 101: 555-566. https://doi.org/10.1094/PHYTO-08-10-0228

Jacobs K., Bergdahl D.R., Wingfield M.J., Halik S., Seifert K.A., ..., Wingfield B.D., 2004. Leptographium wingfieldii introduced into North America and found associated with exotic Tomicus piniperda and native bark beetles. Mycological Research 108: 411-418. https://doi.org/10.1017/s0953756204009748

Kajii C., Morita T., Jikumaru S., Kajimura H., Yamaoka Y., Kuroda K., 2013. Xylem dysfunction in Ficus carica infected with wilt fungus Ceratocystis ficicola and the role of the vector beetle Euwallacea interjectus. International Association of Wood Anatomists Journal 34: 301-312. https://doi.org/10.1163/2294193200000025

Kajitani Y., Masuya H., 2011. Ceratocystis ficicola sp. nov., a causal fungus of fig canker in Japan. Mycoscience 52: 349-353. https://doi.org/10.1007/s10267-0110116-5

Kato K., Hirota K., Miyagawa T., 1982. A new disease, Ceratocystis canker of fig caused by Ceratocystis fimbriata Ellis et Halsted. Plant Protection 36: 55-59 (in Japanese).

Kislev M.E., Hartmann A., Bar-Yosef O., 2006. Early domesticated fig in the Jordan Valley. Science 312: 1372-1374. https://doi.org/10.1126/science. 1125910

Li Q., Harrington T.C., McNew D., Li J., 2017. Ceratocystis uchidae, a new species on Araceae in Hawai' $\mathrm{i}$ and Fiji. MycoScience 58: 398-412. https://doi. org/10.1016/j.myc.2017.06.001

Marincowitz S., Barnes I., De Beer Z.W., Wingfield M.J., 2020. Epitypification of Ceratocystis fimbriata. Fungal Systematics and Evolution 6(1): 289-298. https://doi. org/10.3114/fuse.2020.06.14

Moller W.J., De Vay J.E., 1968. Carrot as a species-selective isolation medium for Ceratocystis fimbriata. Phytopathology 58: 123-124.

Morita T., Jikumaru S., Kuroda K., 2016. Disease development in Ficus carica plants after inoculation with Ceratocystis ficicola. (1) Relationship between xylem dysfunction and wilt symptoms. Japanese Journal of Phytopathology 82: 301-309. (In Japanese with English summary). https://doi.org/10.3186/jjphytopath.82.301

Nasution, A., Glen, M. Beadle, C., Mohammed C., 2019. Ceratocystis wilt and canker - a disease that compromises the growing of commercial Acacia-based plantations in the tropics. Australian Forestry 82: 80-93. https://doi.org/10.1080/00049158.2019.1595347 
Pasura A., Harrington T.C., 2004. Two undescribed species in the Ceratocystis fimbriata complex on Ficus and Colocasia from Asia and Polynesia. Phytopathology 94 (supl.): S160-S161 (Abstr.).

Soulioti N., Tsopelas P., Woodward S., 2015. Platypus cylindrus, a vector of Ceratocystis platani in Platanus orientalis stands in Greece. Forest Pathology 45: 367372. https://doi.org/10.1111/efp.12176.

Sumida S. Kajit C., Morita T., Kuroda K., 2016. Disease development in Ficus carica seedlings after inoculation with Ceratocystis ficicola. (2) Microscopic analysis of the host-pathogen interaction and internal symptoms. Japanese Journal of Phytopathology 82: 310-317. (In Japanese with English summary). https://doi.org/10.3186/jjphytopath.82.310

Stamatakis A., 2014. RAxML Version 8: A tool for phylogenetic analysis and post-analysis of large phylogenies. Bioinformatics 30: 1312-1313. https://doi. org/10.1093/bioinformatics/btu033.

Swofford D.L., 2002. PAUP*. Phylogenetic Analysis Using Parsimony (*and other methods). 4 edn. Sinauer Associates, Sunderland. https://doi. org/10.1111/j.0014-3820.2002.tb00191.x

Tjamos E.C., Tsopelas P., Soulioti N., Palavouzis S., Antoniou P., Paplomatas E.J., 2018. A serious infection of fig trees by Ceratocystis sp. in Greece: First report of the pathogen in Europe. Abstracts of the 19th Greek Phytopathological Congress, Hellenic Phytopathological Society, Athens, Greece, October 30-November 1, 2018, p. 31 (in Greek).

Tsopelas P., Santini A., Wingfield M.J., De Beer W., 2017. Canker stain: A lethal disease destroying iconic plane trees. Plant Disease 101: 645-658. https://doi. org/10.1094/PDIS-09-16-1235-FE

Yakushiji H., Morita T., Jikumaru S., 2019. Ceratocystis canker resistance in $\mathrm{BC} 1$ populations of interspecific hybridization of fig (Ficus carica) and F. erecta. Scientia Horticulturae 252: 71-76. https://doi. org/10.1016/j.scienta.2019.03.039 